\title{
Knowledge, Attitude and Practices Regarding Extreme Environments and Cold Adaptation at Extreme Altitudes on the Himalayan Ranges
}

\author{
Inam Danish Khan ${ }^{1 *}$ \\ ${ }^{1}$ Army College of Medical Sciences and Base Hospital, New Delhi, India
}

Corresponding Author: Inam Danish Khan, MD, Associate Professor of Microbiology, Army College of Medical Sciences and Base Hospital, New Delhi 110010, India. Tel: +91-8076324060, Fax: +91-11-25693490, Email: titan_afmc@yahoo.com

Received September 5, 2019; Accepted February 26, 2020; Online Published March 5, 2020

\begin{abstract}
Introduction: Extreme-altitudes (5500 m/18045 ft and higher) pose environmental, psychophysiological, infrastructural, logistic, and ergonomic challenges that question explorer's adaptability and mission-efficiency due to isolation, monotony, intimidating environment and terse health conditions. The assessment of an explorer's comprehensive adaptability in extreme-altitudes is of paramount importance in ensuring mission-preparedness. Knowledge, attitude, and practices (KAP) of explorers staying on extreme-altitudes was assessed through personal interview technique.

Methods: 125 healthy, acclimatized, mountain-trained explorers staying above $4570 \mathrm{~m} / 15000 \mathrm{ft}$ in winter-season for at least 30 days on extreme-altitudes were assessed by a single cross-sectional study through personal interviews on KAP related to extreme-altitude and cold-adaptation.

Results: Mean duration of stay on extreme-altitude was 55.7 days. All explorers knew about difficulties and health-problems at extremealtitude. All explorers felt that mountain-training and acclimatization were beneficial. $92 \%$ felt that mission tenure of 90 days on the extreme-altitude was adequate. $92.8 \%$ felt they were adequately trained for the extreme-altitude; however, only $52 \%$ felt confident about health-training. $66.4 \%$ did preventive rewarming of extremities. $66.4 \%$ regularly smoked/chewed tobacco. $57.6 \%$ had sleep problems and $64 \%$ had altered appetite. $26.4 \%$ felt difficulties related to living conditions, infrastructure, and logistics.

Conclusion: Explorers at extreme-altitude exhibited adequate knowledge and performed activities with progressive attitude and healthy practices. Explorers endured altered psychophysiology at extreme-altitude and regarded the utility of training and acclimatization programs. Knowledge-practice gap existed towards tobacco consumption. There was a felt need for the improvement of living conditions, infrastructure, logistics, and health-related training.

Keywords: Health Knowledge, Attitudes, Practice, Psychophysiology
\end{abstract}

Citation: Khan ID. Knowledge, attitude and practices regarding extreme environments and cold adaptation at extreme altitudes on the himalayan ranges. Int J Travel Med Glob Health. 2020;8(1):18-21. doi:10.34172/ijtmgh.2020.03.

\begin{abstract}
Introduction
Extreme-altitudes, defined as the altitude above $5500 \mathrm{~m} / 18045$ $\mathrm{ft}$, have long been a matter of concern for explorers worldwide. Environmental, physiological, psychological, infrastructural, logistic, and ergonomic challenges question individual adaptability and mission efficiency. Despite advances in meteorology, disaster management, mountain medicine, mountain technology, and logistics management; extreme altitudes remain resource, effort and economically intensive to the exchequer with wide ramifications to numerous stakeholders. Extreme-altitudes demand unflinching physical ability, mental agility, mountain training, and group cohesiveness for successful mission-operations. However, the mission-oriented explorer faces extreme stressors in the
\end{abstract}

absence of socio-emotional support systems. ${ }^{1,2}$

Extreme-altitude locations are exclusively existent in the Himalayan terrain. ${ }^{3,4}$ Extremes of altitude $(5500 \mathrm{~m} / 18045$ $\mathrm{ft}-7010 \mathrm{~m} / 23000 \mathrm{ft})$, cold $\left(-20^{\circ} \mathrm{C}\right.$ to $\left.-70^{\circ} \mathrm{C}\right)$, hypoxia, terrain hazards (glaciated terrain/ snowbound terrain/ice-sheet/ crevasses/ avalanches, etc), weather hazards (blizzards/ snow storms/ whiteouts/ heavy snowfall/ intense radiation/ lightning, etc), health hazards (mountain sickness, pulmonary edema, frostbite, etc), psychosocial hazards (human isolation, monotony, intimidating and hostile environment, etc), infrastructural and ergonomic stringency (accommodation, movement, transportation, communication, difficult activities of daily living), and relative lack of experience, pose colossal challenges to explorers. ${ }^{3-5}$

Copyright $(\odot 2020$ The Author(s). This is an open-access article distributed under the terms of the Creative Commons Attribution License (http:// creativecommons.org/licenses/by/4.0), which permits unrestricted use, distribution, and reproduction in any medium, provided the original work is properly cited. 
The assessment of an explorer's comprehensive adaptability in extreme altitudes is of paramount importance in ensuring mission preparedness. Individual knowledge, attitude, and practices (KAP) has a direct impact on explorers' courage, confidence, discipline, enthusiasm, and endurance. Rapidly changing perspectives in modern exploratory missions mandate a regular assessment of KAP amongst explorers in extreme-altitude and cold environments. ${ }^{4}$ In the first of its kind, the study intends to assess KAP of explorers pertaining to extreme-altitude and cold-adaptation staying on extremealtitude, the results of which can be extrapolated to all extreme-altitudes.

\section{Methods}

A total of 125 healthy, acclimatized, mountain trained, male explorers staying above $5550 \mathrm{~m} / 18045 \mathrm{ft}$ for at least 30 days in the winter season of 2016-2017 on an extreme altitude were selected under inclusive sampling after a pilot study amongst 25 respondents for validation of questionnaire, for single cross-sectional research after approval and written informed consent. A personal interview was conducted by the author face to face in vernacular language and responses were recorded on a specifically designed proforma. The proforma covered aspects of KAP on extreme altitude, cold adaptation, and glacier habitation, improved and validated through pilot study for the removal of language, comprehension and response bias, and rephrased similar questions for internal consistency. Clinico-demographic parameters and previous experience were noted. Knowledge about health issues on extremealtitudes, attitude towards extreme-altitude, cold-adaptation and related practices were assessed. Questions were asked on acclimatization, extreme-altitude duration, extreme-altitude training, preventive practices, tobacco/alcohol consumption, sleep, appetite, memory, stress, lethargy, group behavior, beliefs, and problem areas. A direct observation during the course of the interview was made to correlate with explorers' responses. Inbuilt control was used wherein individual responses were taken positive only if the explorer reported them in increased intensity or frequency while staying at extreme altitudes compared to his previous experiences as an explorer. Twice daily medical report on preventive healthcare comprising preventive rewarming of extremities twice daily irrespective of cold exposure, consumption of $1 \mathrm{~L}$ of warm water twice daily and physical exercise was taken from all explorers through hand-held radio communication devices. Descriptive statistics were worked out.

\section{Results}

The respondents $(\mathrm{N}=125)$ were healthy, acclimatized, mountain and extreme-altitude trained male explorers of Indian origin with a mean age of $29.35 \pm 6.07$ years. $67.2 \%$ of explorers were aged between $18-30$ years. The mean period of stay at extreme-altitudes was $55.7 \pm 23.42$ days (Figure 1). The mean years of formal education was $11.19 \pm 1.41$ years. $81.6 \%$ were married and $80.8 \%$ were parents.

All explorers were knowledgeable about difficulties of extreme-altitudes, including health problems. They were

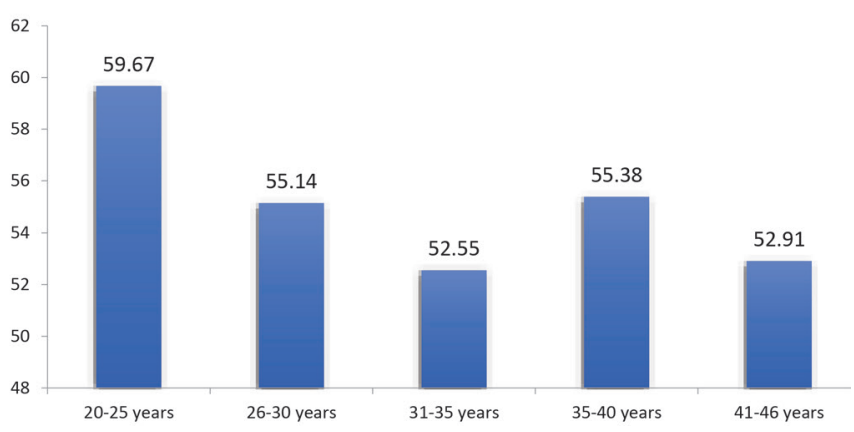

Figure 1. Mean Stay (Days) on Extreme-Altitude in Comparison to Age (Vertical axis depicts the number of participants).

also aware of preventive measures although only $52 \%$ of explorers were aware of the treatment of common diseases. They felt that mountain and extreme-altitude training and acclimatization was beneficial to them. $92.8 \%$ felt they were adequately trained for the extreme-altitude; however, only $52 \%$ felt confident about training on health aspects. They affirmed that they would report any medical problem at the earliest.

All explorers were carrying cold weather clothing, however, only $76.8 \%$ were carrying preventive ointments, despite pre-induction advice. They attempted to keep themselves physically active at the extreme-altitude. They followed instructions on increased water intake, proper clothing, and care of exposed body parts. $66.4 \%$ performed preventive rewarming of hands and feet at least once a day. $19.2 \%$ were reformed tobacco consumers and $14.4 \%$ had never consumed tobacco. However, all refrained from alcohol and recreational drugs due to pre-induction pre-conditioning against alcohol but not against tobacco. Alcohol availability at the extremealtitude was restricted/legislated compared to tobacco products which were easily available, could be covertly carried and left fewer identifiable features after consumption.

$57.6 \%$ of explorers experienced sleep problems, and $64 \%$ had altered appetite. $48.8 \%$ had a craving for sweets and $29.6 \%$ for salted foods. $83.2 \%$ admitted having developed food fads during their stay at extreme-altitude (Figure 2). However, when given three words to remember and asked subsequently, all of them were able to recall. All explorers used to abide by certain ethos/beliefs/superstitions which most commonly included the existence of supernatural entities.

Group-commanders affirmed preventive healthcare practices. The observations correlated with corresponding responses regarding cold weather clothing and assessment of cold injuries through the examination of extremities. $80 \%$ of explorers were initially hesitant in communicating freely which was improved with the establishment of rapport. However, they were concerned about adverse peer response, poor feedback, and deinduction as consequences to their answers to which anonymity acted as reassurance.

\section{Discussion}

This study is the first of its kind at extreme-altitude. There is a paucity of research work and experience on extreme-altitude due to extremely tough living conditions and low resource 
120

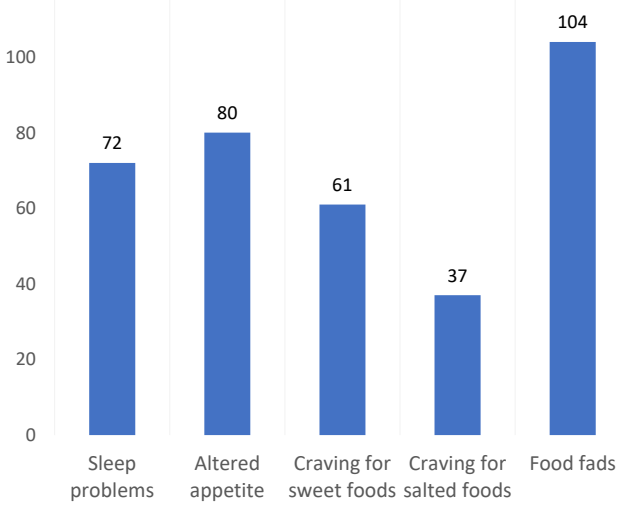

Figure 2. Physiological Problems Reported by Explorers at Extreme-Altitude (Vertical axis depicts the number of participants).

settings making research work highly implausible., ${ }^{2,3,6}$ During the conduct of the study in the winter months of December and January with temperatures reaching as low as $-70^{\circ} \mathrm{C}$, movement, communication, logistic and aviation capabilities were severely paralyzed by inclement weather conditions. ${ }^{5-7}$ The environment remained monotonous, isolated and intimidating. All explorers were staying in fuel-heated and poorly ventilated shelters/tents with survival on dried/ canned food and snow-melted water. Outreach programs were difficult and discouraging. The research plan and KAP proforma were designed to cater for issues specific to extremealtitude while accommodating the deficiencies in the absence of specific guidelines for such an effort.

Extreme-altitudes extend numerous stressors to participants adversely affecting mission objectives. Extreme-altitude, cold preparedness, and adaptation are facilitated by supervised acclimatization and pre-induction mountain-altitude training programs. Despite instituted staged-graded acclimatization protocols, complete acclimatization may not be attained at extreme altitudes above $5500 \mathrm{~m} / 18045 \mathrm{ft}$ and explorers remain prone to extreme-altitude sickness. ${ }^{3,6,8}$ Extremealtitude pre-induction training contributes to explorers' fear, alleviation, and confidence in the terrain; however, the effects are variable depending upon explorers' place of residence, physical fitness, preconditioning, motivation, and willingness to learn. Further, the benefits of these efforts may be rendered ineffective due to the negative attitude and practices of explorers, thereby emphasizing the assessment of KAP amongst explorers in extreme altitudes.

KAP incorporating chosen indicators was assessed through person to person interview amongst healthy, acclimatized, mountain and extreme-altitude trained, experienced and physically/mentally robust male explorers exposed to winter season on extreme-altitudes. Assessment technique using indicators chosen by explorers provides an objective evaluation of KAP. ${ }^{9,10}$ The overall experience as an explorer forms an inbuilt comparison for their responses when a change in frequency or severity is mentioned.

While the interview was conducted by the author, a medical doctor, who was trusted by the explorers, responses may be affected due to various factors. On the one hand, the resoluteness and resilience of explorers may prevent them from giving responses to questions perceived by them as unimportant, and on the other hand, it is likely that people will not hide facts due to either primary conditioning regarding a doctor's visit or the power of persuasion and influence of the doctor. Mental stressors such as fear of ill health of self, ill health of peers, evacuation, deinduction, and consequences of decision making may affect responses. Confounding factors such as the difference in language, level of understanding, intellect, socio-cultural influence, external pressure, compassion fatigue, altered sleep, and memory may play a role in interview-based research in extreme environments. ${ }^{2,10,11}$ The responses may also be influenced by the explorers' experience in the 30-day exposure of harsh winters. It may be difficult to distinguish physical and psychological symptoms in extreme environments, as well. ${ }^{8,12-14} \mathrm{~A}$ KAP generated result is reliable though needs to be carefully interpreted in view of existing limitations of selection bias, interviewer bias, and response bias which may affect the validity and generalizability. ${ }^{10}$

Even though the explorers were knowledgeable about conditions of extreme altitude, they did not exhibit control over tobacco smoking, revealing a knowledge-practice gap. Hypoxia and extreme cold together may contribute to disturbed sleep, reduced appetite, dehydration, lack of concentration, fatigue, irritability, lethargy, and depression. ${ }^{15,16}$ Decreased sleep quality and increased sleep disturbance has been reported amongst Indian subjects at high altitude. ${ }^{17}$ A study in simulated altitude $4500 \mathrm{~m}$ normobaric chamber revealed worsening of sleep time, sleep efficiency, vigour, attention, visual and working memory, concentration, executive functions, inhibitory control, speed of mental processing, depressive mood, anger, and fatigue. ${ }^{18}$ Studies of personnel who have spent winters in Antarctica revealed that $64.1 \%$ reported some problems in sleep, $62.1 \%$ reported feeling depressed, $47.6 \%$ reported feeling more irritable than usual and $51.5 \%$ reported difficulty with concentration or memory. ${ }^{17}$ Food craving and fads may be attributed to altered appetite. Extreme-altitude stressors can induce physiological and psychological symptoms. ${ }^{19}$ Religious and cultural beliefs including superstitions are expected in Indian explorers due to their sociocultural preconditioning. The suggestions from explorers emanated from felt needs mandating periodical review. Communication facilities need to be strengthened amidst terrain compartmentalization and dead space limitations at extreme-altitudes. ${ }^{11}$ The reported preventive healthcare practices could not be cross-checked due to limitations of extreme-altitude.

An explorer forms an independent unit that thus is a leadership and individual responsibility. Altitude care has a direct correlation with KAP of explorers. Many stressors in extreme-altitudes are beyond control and need to be accepted. However, it is important to understand the necessity of aggressive intervention to every possible problem, including those perceived as minor issues.

Mountain-healthcare can be delivered at expert (doctor), team (buddy-care) and individual (self-care) level. Large expeditions rely largely on expert level healthcare delivery by doctors and/or paramedics. The ratio of doctors and paramedics to the number of explorers is low at extreme- 


\section{Research Highlights}

\section{What Is Already Known?}

Extreme-altitudes $(5500 \mathrm{~m} / 18045 \mathrm{ft}$ and higher) pose environmental, psychophysiological, infrastructural, logistic and ergonomic challenges that question explorer's adaptability and mission-efficiency due to isolation, monotony, intimidating environment, and terse health conditions.

\section{What This Study Adds?}

1. In the first of its kind, knowledge, attitude, and practices (KAP) related to extreme-altitude and cold-adaptation assessed at extreme attitude revealed a knowledge practice gap related to tobacco consumption.

2. Regular KAP assessment using chosen indicators can contribute to strategic planning, mission deployment, formulation of mountain and glacier training doctrines; and capacity building in the participants.

altitudes. Health accessibility, outreach, and evacuation are limited by distance, terrain, communication, aviation capability, and weather conditions. Team level healthcare delivery by fellow explorers warrants attention as the affiliate explorers have the adequate situational understanding and mental adroitness to become the ideal first responder with minimal specialized training. Individual-level healthcare can be boosted by training of participants and equipping them with medicines, however, there is scope for improvement to attain adequate expertise similar to border patrol personnel or armed forces. Incorporation of leading-edge healthcare robots and drones can facilitate outreach, emergency response, and early warning systems capabilities.

Behavioural interventions targeted against tobacco and alcohol consumption can be initiated, encouraged, and legislated by formation leaders. Human resource interventions can be targeted at avoidance of professional isolation and training of participants in first aid, psychological judgment, referral, and counseling. Infrastructural interventions at living shelters and communication need a boost. Ongoing efforts are required to quantify the contributions of various etiologic factors; establish standard operating procedures for decision making; and to identify feasible, effective interventions.

\section{Conclusion}

Explorers at extreme-altitude exhibited adequate knowledge regarding various aspects related to extreme-altitudes. They lived on the extreme-altitude with a progressive attitude and healthy practices. They regarded the utility of training and acclimatization programs. A knowledge-practice gap existed towards tobacco consumption. They endured altered psychophysiology at extreme-altitudes. There was a felt need for the improvement of logistic support systems and healthrelated training. This endeavour will contribute to strategic planning, mission deployment, formulation of mountain and glacier training doctrines; and capacity building in the participants.

\section{Conflicts of Interest Disclosures}

The author declares that he has no conflict of interest.

\section{Ethical Approval}

Ethical approval was covered by the Institutional Committee.

\section{Funding/Support}

None.

\section{References}

1. Ali A. A Siachen peace park: the solution to a half-century of international conflict? Mt Res Dev. 2002;22(4):316-319. doi:10.1659/0276-4741(2002)022 [0316:ASPPTS]2.0.CO;2.

2. Khan ID. Extreme altitude pulmonary oedema (EAPO) in acclimatized soldiers. Med J Armed Forces India. 2012;68(4):339345. doi:10.1016/j.mjafi.2012.04.018.

3. Khan ID. Comorbid cerebral and pulmonary edema at 7010 m/23000 ft: an extreme altitude perspective. Bangladesh J Med Sci. 2015;14(1):153-155. doi:10.3329/bjms.v14i1.17040.

4. Rao KS. Other medical illnesses aggravated by high altitude. In: Anand AC, Narula AS, Kakkar R, Kalra R, eds. Textbook of Environmental Emergencies. Pune, India: Department of Internal Medicine, Armed Forces Medical College; 2006:26-9.

5. Khan ID. On-site management of frostbite in the Himalayas. Int J Travel Med Glob Health. 2017;5(1):28-32. doi:10.15171/ ijtmgh.2017.05.

6. Khan ID. Cerebral venous sinus thrombosis masquerading as high altitude cerebral edema at extreme altitude. Int J Travel Med Glob Health. 2016;4(3):96-98. doi:10.21859/ijtmgh-040306.

7. Khan ID. Extreme altitude chronic mountain sickness misdiagnosed as high altitude cerebral edema. Int J Travel Med Glob Health. 2016;4(4):132-134. doi:10.21859/ijtmgh-040408.

8. Subba PS. Director general, armed forces medical services, New Delhi. Report no. DGAFMS/AFMRC/1/64; 1964.

9. Bashir K. Psychiatric morbidity amongst the troops deployed at Siachen. Pak Armed Forces Med J. 2008;58(1):3-9.

10. Khan ID. KAPB study on contraceptives among married armed forces personnel. Indian Journal for the Practising Doctor. 2008;5(2):1-10.

11. Grau LW, Falivene J. Mountain combat: hard to move, hard to shoot, even harder to communicate. J Slav Mil Stud. 2006;19(3):619-625. doi:10.1080/13518040600868164.

12. Bardwell WA, Ensign WY, Mills PJ. Negative mood endures after completion of high-altitude military training. Ann Behav Med. 2005;29(1):64-69. doi:10.1207/s15324796abm2901_9.

13. Grau LW, Jorgensen WA. Medical Implications of High Altitude Combat. Fort Sam Houston: U.S. Army Medical Department Center and School; 2003.

14. Khan ID, Sahni AK. Possession syndrome at high altitude (4575 m/15000 ft). Kathmandu Univ Med J (KUMJ). 2013;11(43):253255. doi:10.3126/kumj.v11i3.12516.

15. Castro CA, Hoge CW, Cox AL. Battlemind training: building soldier resiliency. In: Human Dimensions in Military Operations: Military Leaders' Strategies for Addressing Stress and Psychological Support. Meeting Proceedings RTO-MP-HFM-134; 2006. Neuilly-sur-Seine, France.

16. Szymczak RK, Sitek EJ, Sławek JW, Basiński A, Siemiński M, Wieczorek D. Subjective sleep quality alterations at high altitude. Wilderness Environ Med. 2009;20(4):305-310. doi:10.1580/10806032-020.004.0305.

17. Thakur L, Anand JP, Malhotra AS, Sharma YK, Panjwani U. Sleep architecture at $4300 \mathrm{~m}$ altitude in a sample of Indian lowlanders. Indian J Physiol Pharmacol. 2012;56(4):295-300.

18. de Aquino Lemos V, Antunes HK, dos Santos RV, Lira FS, Tufik S, de Mello MT. High altitude exposure impairs sleep patterns, mood, and cognitive functions. Psychophysiology. 2012;49(9):1298-1306. doi:10.1111/j.1469-8986.2012.01411.x.

19. Palinkas LA. Going to extremes: the cultural context of stress, illness and coping in Antarctica. Soc Sci Med. 1992;35(5):651-664. doi:10.1016/0277-9536(92)90004-a. 